\title{
Distribution of Community Acquired Typhoid Fever among Febrile Patients Attending Clinics in Bushenyi, Uganda: Case Study of the Year 2005
}

\section{Ezera Agwu*}

Tropical Disease Research Unit, Department of Medical Microbiology, Faculty of Biomedical Sciences, School of Health Sciences, Kampala International University, Western Campus, Ishaka, Bushenyi, Uganda

\begin{abstract}
Background/Objective: Febrile illnesses have continued to escalate in South-Western Uganda despite using many multidisciplinary studies and interventions (weakened by poor resources) to control the syndrome. To appraise the burden of typhoid in regional febrile illnesses, this laboratory based retrospective analytical study was undertaken to outline the distribution of community acquired typhoid fever among febrile patients attending clinics in Bushenyi, Uganda.
\end{abstract}

Methods: After ethical approval and with standard methods, six hundred and eighty seven data-files (311 from males and 376 from females) of recruited febrile, typhoid positive hospital attendees in Bushenyi were analyzed with particular attention to socio-demographic impact on typhoid distribution.

Results: From the age bracket 10-19 years, males, with 36.6\% typhoid, attending Bushenyi Medical center and females, with $33.8 \%$ typhoid attending Comboni hospital had the highest typhoid distribution in this survey. Other results include males: $10-19 y$ years and above 60 years old from Comboni hospital with $28.6 \%$ and $22.2 \%$ typhoid distribution, including $24.6 \%$ typhoid distribution shown among males 20-29years old attending Ishaka Adventist Hospital. However, females above 60years and 10-19 years old attending Bushenyi medical center had $32.8 \%$ and $25 \%$ typhoid distribution respectively; including $24.7 \%$ typhoid among females aged $20-29$ years old, attending Comboni hospital. Typhoid: was highest in the low-income class, lowest in the high-income class and uniformly distributed from January to December.

Conclusions: Typhoid is highly (36.6\%) prevalent among febrile patients aged (10-29 years old) attending clinics in Bushenyi and spread depends on age, sex, socio-economic status and season. The strategic impact of typhoid on the teenage and early adulthood aged- 10-29 years is noteworthy. Hygiene education and monitoring of the street-food trade are recommended typhoid control measure.

Keywords: Typhoid; Febrile patients; Uganda

\section{Introduction}

Febrile illness has remained a public health challenge across all ages, especially in resource poor countries despite clear advances made in understanding its epidemiology management and control. To date, the incidence and relative importance of febrile illnesses are still not known in many African regions because of the difficulties associated in measuring febrile illness in a population with poor diagnostic facilities [1,2]. One of the most important tropical diseases known to cause febrile illness is typhoid, an acute systemic disease of Salmonella enterica serovar Typhi, transmitted by the fecal-oral route through contaminated food and water [3]. Typhoid has prevailed in the developing countries because of poor personal and environmental sanitation and because of the emergence of resistance to the antibiotics used for treatment [4]. The true burden of typhoid may generally be difficult to quantify because most of the clinical pictures are easily mistaken for many other febrile illnesses including malaria, West-Nile and HIV viruses [1].

Widal serological test has remained a significant diagnostic tool in resource poor settings like in Bushenyi, Uganda, despite the growing skepticism among many researchers and even health care providers about the reliability and reproducibility of the test. Widal serological test was originally meant to detect agglutinating antibodies to lipopolysaccharide using acute- and convalescent-phase serum samples taken roughly 10 days apart but recently, the test has been adapted for use with a single, acute-phase serum sample [5-7].

Over $80 \%$ of Ugandan districts are typhoid endemic with Central and Western districts topping the list [8]. Outbreak of inpatient cases of gut perforation with unknown numbers of death are common among operated febrile typhoid patients in this region. In Bushenyi district similar outbreaks have easily been attributed to delay of patient's referral to hospitals, lack of antibiotic protocol, lack of illiostomy bags, understaffing, and cost of care and above all, lack of culture and sensitivity data. It is therefore not clear if there is silent epidemic of typhoid fever in Bushenyi district with high endemicity of febrile illnesses and common cases of inpatient gut perforation? This

${ }^{*}$ Corresponding author: Dr. Ezera Agwu, Tropical Disease Research Unit Department of Medical Microbiology, Faculty of Biomedical Sciences, School of Health Sciences, Kampala International University, Western Campus, Ishaka, Bushenyi, Uganda, Tel: +256782101486/+256703129679; E-mail: agwuezera@yahoo.com, agwuezera@gmail.com

Received June 15, 2011; Accepted September 02, 2011; Published Septembe 05, 2011

Citation: Agwu E (2012) Distribution of Community Acquired Typhoid Fever among Febrile Patients Attending Clinics in Bushenyi, Uganda: Case Study of the Year 2005. J Medical Microbiol Diagnosis 1:101. doi:10.4172/2161-0703.1000101

Copyright: (c) 2012 Agwu E. This is an open-access article distributed under the terms of the Creative Commons Attribution License, which permits unrestricted use, distribution, and reproduction in any medium, provided the original author and source are credited. 
underscores the need for a frequent and updated situational analysis of the regional epidemiology of typhoid disease, which may silently be devastating Bushenyi inhabitants. To appraise the burden of typhoid in regional febrile illnesses, this laboratory based retrospective analytical study was undertaken to outline the distribution of community acquired typhoid fever among febrile patients attending clinics in Bushenyi, Uganda.

\section{Materials and Methods}

\section{Study design, Center and data inclusion criteria}

This is a retrospective cross-sectional laboratory based study, conducted in three main Bushenyi district hospitals (Ishaka Adventist Hospital; Comboni Hospital and Bushenyi Medical Center), randomly selected because they: see a sizable number of febrile patients attending clinics in Bushenyi; have side laboratories where serological tests are done for febrile and other tropical illnesses and have consistent clinical and laboratory data for the year 2005. All attempts to include more recent data from the 3 hospitals were not possible because of poor information storage and retrieval methods, occasioned by change in hospital policies in which patients are now allowed to go home with their files. The data of 687 febrile typhoid patients (confirmed clinically by a clinician during first hospital visit and serologically confirmed at the hospital laboratories), who attended 3 main clinics in Bushenyi district in the year 2005, were included in this study. Laboratory data not confirmed by hospital record and hospital records not confirmed by laboratory data were excluded from this study. Also excluded were patients' data whose typhoid was detected after seven days of hospital admission.

\section{Ethical considerations}

The ethical review board of: Kampala International University and Bushenyi District health division approved this survey. The management of the three hospitals which participated also consented for patient's data to be used in this study.

\section{Sample analysis}

In retrospect, laboratory and clinical data of 687 febrile typhoid patients who attended Ishaka Adventist Hospital; Comboni Hospital and Bushenyi Medical Center in Bushenyi district of Uganda, between January 1, and December 31, 2005 were retrieved from laboratory and hospital records for analysis. Patients were counted if his/her records fulfill two conditions: first; a hospital records indicating that he or she was presumptively diagnosed of typhoid after clinical examination during first visit (up to seven days after admission) at the three participating hospitals and secondly, a laboratory record of the same patient serologically confirming typhoid. The data analyzed were from 687 patients who fulfilled the inclusion criteria and who were subsequently registered at the 3 participating hospitals between January 1, 2005 and December 31, 2005.

A close look at the serological methods showed that the 3 participating hospitals adopted the Widal serological procedure similar to the standard protocol which we followed in our former Nigeria study [9]. A titre of greater than $1 / 100$ to either $\mathrm{O}$ or $\mathrm{H}$ antigens of Salmonella enterica serotype Typhi in a single acute-phase sera were taken to be indicative of typhoid fever $[9,10]$. The results of Widal tests were interpreted together with patient's clinical record as suggested by Saha et al. [7].
To access the impact of social class and income status on typhoid distribution, all the participants were arbitrarily allocated to a social class with the routine data collected about their daily expenses. Three social classes were identified and designated as either "Low class" (L) (Live on less than one US\$ dollar a day), "Middle class" (M) (Live on 1-10 US\$ dollar a day) or "High class" (H) (Live on above 1-10 US\$ dollar a day).

To assess the relationship between seasonal variations and typhoid distribution participant's hospital attendance was grouped into four (three monthly).

\section{Results}

In Table 1 below, the highest typhoid distribution was observed among males aged 10-19 years and slightly varied in two of the participating hospitals as follows: $28.6 \%$ in Comboni hospital and $36.6 \%$ in Bushenyi Medical Center, while the highest distribution of typhoid in the third participating hospital (Ishaka Adventist Hospital), was $24.6 \%$, common among males aged 20-29 years. On the other hand, Table 1 also shows females aged 10-19 years, with the highest typhoid distribution of $33.8 \%$ in Comboni hospital, and $32.8 \%$ in Bushenyi Medical Center. Again, the highest typhoid distribution recorded in Ishaka Adventist Hospital was 24.3\% and among females aged 20-29 years. Other results and shown in Table 1.

Typhoid distribution was clearly high among the low-income class and low among the high-income class in the study centers and in both male and females (Table 2). Specifically, highest typhoid distribution of $68.3 \%$ was found among males of low income class who attended Bushenyi Medical Center. This was followed by: 62.3\% typhoid distribution among females of low income class in Comboni hospital and 55.3\% typhoid distribution among females of low income class in Ishaka Adventist Hospital. The rest of the result is shown in (Table 2) below.

In (Table 3) below, it appears typhoid distribution was uniformly distributed from January to December, because the 3 sentinel centers recorded peak prevalence in all the months depicting equal monthly prevalence in a year. Female participants with $39.0 \%$ typhoid distribution in the months of April-June at Comboni hospital was the highest typhoid distribution noted followed by males with $33.3 \%$ typhoid distribution in January-March, at Comboni hospital and males with 32.9\% typhoid distribution in October-December and at Ishaka Adventist hospital. Other results are shown in Table 3.

\section{Discussion}

Although advances in public health and hygiene have virtually led to the disappearance of typhoid fever from many developed countries, the disease remains endemic in developing countries. The clinical diagnosis of typhoid in settings with poor laboratory facilities are difficult because typhoid fever mimics other common febrile illnesses such as malaria; non-typhoid sepsis, tuberculosis, brucellosis, tularaemia, leptospirosis, and rickettsial diseases including viral infections such as dengue fever, acute hepatitis, and infectious mononucleosis [1]. To assist health care providers in the diagnosis typhoid with more confidence in resource poor setting, Walsh et al. [11], suggested a clinical distinction between typhoid fever and enteric fever caused by other gram negative bacilli. Now the broader idea is to develop a multipurpose "fever stick" that may allow the rapid and specific diagnosis of common febrile illnesses in resource poor settings. 
Citation: Agwu E (2012) Distribution of Community Acquired Typhoid Fever among Febrile Patients Attending Clinics in Bushenyi, Uganda: Case Study of the Year 2005. J Medical Microbiol Diagnosis 1:101. doi:10.4172/2161-0703.1000101

Page 3 of 4

Overview of results obtained from the 3 participating hospitals indicates that typhoid was most common (24.3\% to $36.6 \%)$ among participants aged 10-29 years, with females generally having higher infection than males (Table 1). This is different from similar population based South Asia study in which children less than 5 years old had highest typhoid distribution $[12,13]$ that other age brackets studied. Four factors could explain the observed high prevalence of typhoid among the age groups 10-29 years in Bushenyi District of Uganda. First, high consumption of unpasteurized milk obtained manually and un-aseptically from local cows. Since this milk was consumed by all participants across all the age brackets, it may be difficult to associate high typhoid distribution observed among the age group 10-29 years with high milk consumption unless infection dose and other underlying illness [2] played a part. Second, poor personal and environmental hygiene including changing lifestyle towards high passion for precooked food and roasted meat from road side vendors prepared with poor hygiene in Bushenyi district [9]. Third, possible exposure of participants to untreated contaminated water during recreation in the available lakes, ponds, cesspools and even drinking of untreated water from water storage tanks and underground reservoirs may have played a part in the observed result. Fourth and finally, transmission of acute cases of typhoid to, or by care givers may have been by direct contact especially if asymptomatic typhoid carries are involved.

The role of socio-economic status in the spread of typhoid in Bushenyi during this year under investigation was also determined by arbitrarily dividing the entire population into: low income, middle income and high income classes respectively (Table 2). The obtained result depicts a decreasing trend of typhoid distribution from low to high income class. Emergence of multi-drug resistance [13-15], poor per capita income and high cost of diagnostic services including poor health management services and lack of adequate disease (typhoid) surveillance which would have warranted appropriate intervention

\begin{tabular}{|c|c|c|c|c|c|c|}
\hline & \multicolumn{3}{|c|}{} & \multicolumn{3}{|c|}{ N=687 } \\
\hline Age range Years & Comboni $\mathbf{n = 6 3}$ & $\begin{array}{c}\text { Number (\%) positive Males } \\
\mathbf{n = 2 0 7}\end{array}$ & $\begin{array}{c}\text { BMC } \\
\mathbf{n = 4 1}\end{array}$ & $\begin{array}{c}\text { Comboni } \\
\mathbf{n = 7 7}\end{array}$ & $\begin{array}{c}\text { IAH positive Females } \\
\mathbf{n = 2 3 5}\end{array}$ \\
\hline$<9$ & $5(7.9)$ & $47(22.7)$ & $3(7.3)$ & $4(5.2)$ & $44(18.7)$ & $4(6.3)$ \\
\hline $10-19$ & $18(28.6)$ & $38(18.3)$ & $15(36.6)$ & $26(33.8)$ & $43(18.3)$ & $21(32.8)$ \\
\hline $20-29$ & $11(17.5)$ & $51(24.6)$ & $8(19.5)$ & $19(24.7)$ & $57(24.3)$ & $14(21.9)$ \\
\hline $30-39$ & $4(6.3)$ & $26(12.6)$ & $2(4.9)$ & $6(7.8)$ & $44(18.7)$ & $3(4.6)$ \\
\hline $40-49$ & $5(7.9)$ & $17(8.2)$ & $5(12.2)$ & $10(13.0)$ & $24(10.2)$ & $4(6.3)$ \\
\hline $50-59$ & $6(9.5)$ & $14(6.8)$ & $2(4.9)$ & $5(6.5)$ & $10(4.3)$ & $2(3.1)$ \\
\hline$>60$ & $14(22.2)$ & $14(6.8)$ & $6(14.6)$ & $7(9.0)$ & $13(5.5)$ & $16(25.0)$ \\
\hline
\end{tabular}

$\mathrm{N}$ : Total number of people positive for typhoid; n: Number of people in each hospital with typhoid; BMC: Bushenyi Medical Center; IAH: Ishaka Adventist Hospital; Comboni: Comboni Health Center

Table 1: Age and Sex Distribution of Typhoid among the Study Population.

\begin{tabular}{|c|c|c|c|c|c|c|c|}
\hline \multirow[b]{3}{*}{ Hospital } & \multicolumn{6}{|c|}{$\mathrm{N}=687$} & \\
\hline & & Male & & \multirow[b]{2}{*}{ Hospital } & \multicolumn{3}{|c|}{ Female } \\
\hline & $\mathbf{L}$ & M & $\mathbf{H}$ & & $\mathbf{L}$ & M & $\mathbf{H}$ \\
\hline Comb $(n=63)$ & $30(47.6)$ & $23(36.5)$ & $10(15.9)$ & Comb $(n=77)$ & $48(62.3)$ & $19(24.7)$ & $10(13.0)$ \\
\hline BMC $(n=41)$ & $28(68.3)$ & $10(24.4)$ & $3(7.3)$ & BMC $(n=64)$ & $32(50.0)$ & $22(34.4)$ & $10(15.6)$ \\
\hline $\mathrm{IAH}(\mathrm{n}=207)$ & $99(47.8)$ & $60(29.0)$ & $48(23.2)$ & IAH $(n=235)$ & $130(55.3)$ & $86(36.6)$ & $19(8.1)$ \\
\hline
\end{tabular}

Key: L: Low income class (Live on <1 US\$ dollar a day); M: Middle income class (Live on 1-10 US\$ dollar a day); H: High income class (Live on above 1-10 US\$ dollar a day); IAH: Ishaka Adventist Hospital; BMC: Bushenyi Medical Center; N: Total number of people positive for typhoid; n: Number of people positive for typhoid in each hospital; Comb: Comboni Health Center

Table 2: Distribution of Typhoid Fever by Socio-Economic Status.

\begin{tabular}{|c|c|c|c|c|c|c|}
\hline \multirow[b]{3}{*}{ Months } & & & & \multicolumn{3}{|c|}{$N=687$} \\
\hline & \multicolumn{3}{|c|}{ Male } & \multicolumn{3}{|c|}{ Female } \\
\hline & $\begin{array}{l}B M C \\
n=41\end{array}$ & $\begin{array}{c}\text { IAH } \\
n=207\end{array}$ & $\begin{array}{c}\text { Comboni } \\
n=63\end{array}$ & $\begin{array}{c}\text { Comboni } \\
n=77\end{array}$ & $\begin{array}{c}\text { IAH } \\
n=235\end{array}$ & $\begin{array}{l}\text { BMC } \\
n=64\end{array}$ \\
\hline Jan-March & $9(22.0)$ & $69(33.3)$ & 8 (12.7) & $11(14.3)$ & 74 (31.5) & $12(18.8)$ \\
\hline April-Jun & $13(31.7)$ & $57(27.5)$ & $16(25.4)$ & $30(39.0)$ & 73 (31.1) & $16(25.0)$ \\
\hline July-Sept & 8 (19.5) & $13(31.7)$ & $20(31.7)$ & $19(24.7)$ & $28(11.9)$ & $16(25.0)$ \\
\hline Oct-Dec & $11(26.8)$ & $68(32.9)$ & $19(30.2)$ & $17(22.1)$ & $60(25.5)$ & 20 (31.2) \\
\hline
\end{tabular}

Key: L: Low class; M: Middle class; H: High class; IAH: Ishaka Adventist Hospital; BMC: Bushenyi medical center; Comboni: Comboni Hospital; N: Total number of people positive for typhoid

Table 3: Prevalence of Typhoid Fever according to Months 
Citation: Agwu E (2012) Distribution of Community Acquired Typhoid Fever among Febrile Patients Attending Clinics in Bushenyi, Uganda: Case Study of the Year 2005. J Medical Microbiol Diagnosis 1:101. doi:10.4172/2161-0703.1000101

Page 4 of 4

may explain the observed typhoid distribution especially in the low income class.

Typhoid was uniformly distributed from January to December (Table 3) indicating no measurable significant seasonal impact on typhoid disease in Bushenyi. However percentage typhoid distribution in (Table 3) still points to the fact that typhoid distribution is slightly raised during the months of October to March (in Ishaka) which are relatively dry months characterized by acute water shortage and drought, significant risk factors for typhoid epidemiology. Seasonal independent risk factors for household spread of typhoid in Bushenyi district may include poor hand washing hygiene, sharing of food from the same plate as tradition demands in some setting, flooding, and consumption of foods from street vendors [16].

Typhoid fever is therefore highly distributed among febrile patients attending clinics in Bushenyi District of Uganda and spread depends on age, sex, socio-economic status and season. The strategic impact of typhoid on the teenage and early adulthood aged-10-29 years is noteworthy. Information storage and retrieval should be improved for more detailed analysis of similar study in the future. Provision of safe drinking water, effective sewage disposal, hygienic food preparation, massimmunization, reliable and inexpensive diagnostic test, availability of cheap effective antibiotics, and vaccination are recommended control and prevention strategies.

\section{Acknowledgement}

Ms Wambua LM, is hereby acknowledged for her assistance in collecting the data from the clinics, the management and staff of Ishaka Adventist Hospital; Comboni Hospital and Bushenyi Medical Center are acknowledged for their assistance in data retrieval and Barrister (Mrs) Agwu QE, for organizing the secretariat where this paper was typed.

\section{Reference}

1. Ihongbe JC, Agwu E, Inyang NJ (2008) Pneumococcal pneumonia complicates presentation of pulmonary tuberculosis and pseudomembranous candidiasis, predictive of unknown HIV infection in Ekpoma Nigeria. The Internet Journal of Microbiology $5: 1-13$

2. Archibald LK, Reller LB (2001) Clinical microbiology in developing countries. Emerg Infect Dis 7: 302-305.

3. Agwu E, Ihongbe JC, Okogun GRA, Inyang NJ (2009) High incidence of coinfection with malaria and typhoid in febrile HIV Infected and AIDS patients in Ekpoma, Edo State, Nigeria. Brazilian Journal of Microbiol 40: 329-332.
4. Mastroeni P, Maskell D (2005) Salmonella' Infections: Clinical, Immunological and Molecular Aspects, ed. (c) Cambridge University Press, www.cambridge. org

5. Schroeder SA (1968) Interpretation of serologic tests for typhoid fever. JAMA 206: $839-840$

6. Parry CM, Hoa NTT, Diep TS, Wain J, Chinh NT, et al. (1999) In Value of a single-tube Widal test in diagnosis of typhoid fever Vietnam. J Clin Microbiol 37: $2882-2886$.

7. Saha SK, Ruhulamin M, Hanif M, Islam M, Khan WA (1996) Interpretation of the Widal test in the diagnosis of typhoid fever in Bangladeshi children. Ann Trop Paediatr 16: 75-78.

8. CDCP, (2003) Integrated Disease Surveillance \& Response/Health Information Bulletin, No 8.

9. Isibor JO, Ogbomoiko DO, Nwobu GO, Agwu E, Okogun GRA, et al. (2003) Serological Survey of patients clinically diagnosed for Enteric Fever in Benin City Edo State Nigeria. Journal of Applied and Basic Sciences 1: 13-16.

10. Agbonlahor DE, Aghahowa MO, Idukpaye O, Agbonlahor FE, Ekundayo AO et al. (1997) Baseline typhoidal antibody levels in apparently healthy Nigerians. Nig Qtr J Hosp Med 7: 242-245.

11. Walsh AL, Smith MD, Wuthiekanun V Suputtamongkol $\mathrm{Y}$, Chaowagul W, et al. (1995) Prognostic significance of quantitative bacteremia in septicemic melioidosis. Clin Infect Dis 21: 1498-1500.

12. Brooks WA, Hossain A, Goswami D, Nahar K, Alam K, et al. (2005) Bacteremic typhoid fever in children in an urban slum, Bangladesh. Emerg Infect Dis 11 326-329.

13. Siddiqui FJ, Rabbani F, Hasan R, Nizami SQ, Bhutta ZA (2006) Typhoid fever in children: some epidemiological considerations. Int J Infect Dis 10: 215-222.

14. Agwu E, Agba MI, Nwobu GO, Ongey JY, Inyang NJ, et al. (2004) Antimicrobial resistant profile of Streptococcus pneumoniae isolated from suspected tuberculosis patients in Ekpoma and its environs. Shiraz Electronic Medical Journal 5: 1-4.

15. Agwu E, Agba MI, Esumeh Fl, Agba MI, Esumeh FI, et al. (2005) Susceptibility status of Streptococcus pneumoniae against streptomycin and rifampicin commonly used for pulmonary tuberculosis. Journal of Applied and Basic Sciences 3: 33-36.

16. Vollaard AM, Ali S, van Asten HAGH, Widjaja S, Visser LG, et al. (2004) Risk Factors for Typhoid and Paratyphoid Fever in Jakarta, Indonesia. JAMA 291 2607-2615. 